Article

\title{
Controlled Deposition of Lead Iodide and Lead Chloride Thin Films by Low-Pressure Chemical Vapor Deposition
}

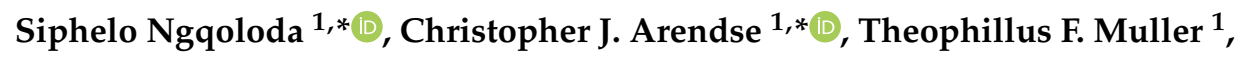 \\ Siphesihle S. Magubane ${ }^{1}\left(\mathbb{D}\right.$ and Clive J. Oliphant ${ }^{1,2}$ \\ 1 Department of Physics and Astronomy, University of the Western Cape, Private Bag X17, Bellville 7535, \\ South Africa; tmuller@uwc.ac.za (T.F.M.); smagubane@uwc.ac.za (S.S.M.); COliphant@nmisa.org (C.J.O.) \\ 2 Materials Characterization, National Metrology Institute of South Africa, Private Bag X34, Lynnwood Ridge, \\ Pretoria 0040, South Africa \\ * Correspondence: sngqoloda@uwc.ac.za (S.N.); cjarendse@uwc.ac.za (C.J.A.); Tel.: +27-21-959-3473 (C.J.A.)
}

Received: 11 November 2020; Accepted: 7 December 2020; Published: 11 December 2020

\begin{abstract}
Lead halide thin films, such as lead iodide $\left(\mathrm{PbI}_{2}\right)$ and lead chloride $\left(\mathrm{PbCl}_{2}\right)$, are used as precursor films for perovskite preparation, which is frequently achieved by vacuum thermal evaporation but rarely by the low-pressure chemical vapor deposition (CVD) method. Here, we report on the deposition of $\mathrm{PbI}_{2}$ and $\mathrm{PbCl}_{2}$ thin films on glass substrates by employing the low-pressure CVD method. The effect of the substrate temperature on the structure and morphology of the lead halide films is investigated. Crystalline films were realized for both lead halides, with $\mathrm{PbI}_{2}$ films showing high texture compared to the reduced texture of the $\mathrm{PbCl}_{2}$ films. Large lateral grain sizes were observed for the $\mathrm{PbI}_{2}$ films with a flat platelet grain morphology and an average grain size up to $734.2 \pm 144.8 \mathrm{~nm} . \mathrm{PbCl}_{2}$ films have columnar grains with an average grain size up to $386.7 \pm 119.5 \mathrm{~nm}$. $\mathrm{The} \mathrm{PbI}_{2}$ films showed a band gap of about $2.4 \mathrm{eV}$, confirming its semiconducting properties, and the $\mathrm{PbCl}_{2}$ had a wide band gap of $4.3 \mathrm{eV}$, which shows the insulating properties of this material.
\end{abstract}

Keywords: lead halide deposition; chemical vapor deposition; substrate temperature; platelets grains; columnar grains; protruding nanowires

\section{Introduction}

Lead halide $\left(\mathrm{PbX}_{2}\right)$ thin films have been studied extensively as precursors for the recently discovered organic-inorganic halide perovskite thin film absorbers for photovoltaic application [1-6]. The deposition of $\mathrm{PbX}_{2}$ ( $X=$ iodine, chlorine, or bromine halide anions) is usually performed in the first step of the sequential two-step deposition of hybrid perovskite thin films [3-6]. A primary hybrid perovskite compound is methyl ammonium (MA) lead iodide $\left(\mathrm{MAPbI}_{3}\right)$, and the mixed halide perovskites are $\mathrm{MAPbI}_{3-x} \mathrm{Cl}_{x}$ and $\mathrm{MAPbI}_{3-x} \mathrm{Br}_{x}(x=1-3)$ [3-6].

Lead iodide $\left(\mathrm{PbI}_{2}\right)$ is a semiconductor with a wide optical band gap $\left(E_{\mathrm{g}}>2.3 \mathrm{eV}\right)$ and a hexagonal structure with a layer-by-layer growth of grains where lead ions are sandwiched between two layers of iodine ions [7-9]. Due to the high atomic weight $\left(\mathrm{Z}_{\mathrm{Pb}}=82, \mathrm{Z}_{\mathrm{I}}=53\right)$ of $\mathrm{PbI}_{2}$, it is applied as a good absorber of X-rays [7-10]. It has also been used as a stable nuclear radiation detector that is able to detect $\mathrm{X}$-rays and Gamma rays $[9,10]$. When $\mathrm{PbI}_{2}$ is used as a scintillation detector, electron-hole pairs are created and thermalized in the conduction and valence bands of this semiconductor upon the absorption of either an X-ray or Gamma ray. $\mathrm{PbI}_{2}$ can further be used for printing, lithography, and $X$-ray imaging, among other applications $[9,10]$.

There are various deposition methods that have been reported for the preparation of $\mathrm{Pb}$ halide thin films or single crystals, such as spray pyrolysis, sol-gel, Bridgman's method, vacuum thermal 
evaporation [6,7,9-17], and, recently, the solution method through spin coating for perovskite thin film preparation [3-5]. $\mathrm{Pb}$ halides have poor solubility in water and hence require dedicated solvents during spin coating, which makes this method of deposition unattractive for scaling up [3,5]. In addition, spin coating from a solution often results in smaller grains of $\mathrm{PbI}_{2}$ and nonuniform layers, which produces poor-quality converted perovskite films [3-5]. Although vacuum thermal evaporation offers high control of the $\mathrm{PbX} X_{2}$ film coverage and thickness, this method requires relatively expensive ultrahigh vacuum systems, thereby making low-pressure CVD a low-cost alternative $[6,9,18,19]$.

The deposition of $\mathrm{PbI}_{2}$ platelets through low-pressure CVD has been reported on muscovite mica substrates. $[1,13,14]$. However, reports on the deposition of $\mathrm{PbI}_{2}$ thin films by the aforementioned method on glass substrates are scarce. On the other hand, $\mathrm{PbCl}_{2}$ deposition by the low-pressure CVD method has not been reported, except through high vacuum thermal evaporation. Since the hybrid perovskite thin film solar cells require deposition on transparent conductive oxides (TCO) substrates, it is important to study the deposition of $\mathrm{Pb}$ halide precursor films on similar substrates as research is still lacking [20,21].

Herein, we report on the deposition of $\mathrm{PbI}_{2}$ and $\mathrm{PbCl}_{2}$ thin films on glass substrates through the low-pressure CVD method. The novelty of this study is demonstrated by the successful deposition of these lead halide films on glass substrates, which has not been achieved before, especially in the case of $\mathrm{PbCl}_{2}$ thin films. The effect of the substrate temperature, which was controlled by adjusting the position of the glass substrates with respect to the heated $\mathrm{Pb}$ halide source zone in the tube furnace, is investigated. Highly crystalline thin films were obtained for both lead halides, with the $\mathrm{PbI}_{2}$ films showing a high texture compared to the reduced texture of the $\mathrm{PbCl}_{2}$ films, as observed from the X-ray diffraction results. Large lateral grain sizes were observed for the $\mathrm{PbI}_{2}$ films with an average grain size of up to $734.2 \pm 144.8 \mathrm{~nm}$. The $\mathrm{PbCl}_{2}$ films, on the other hand, have a columnar grain shape with an average grain size up to $386.7 \pm 119.5 \mathrm{~nm}$. The band gap of the $\mathrm{PbI}_{2}$ film amounts to $2.4 \mathrm{eV}$, confirming its semiconducting properties, whereas the $\mathrm{PbCl}_{2}$ film has a wide band gap of $4.3 \mathrm{eV}$, confirming the insulating property of this material.

\section{Materials and Methods}

\subsection{Lead Halide Film Deposition}

Before deposition, small pieces $\left(2 \mathrm{~cm}^{2}\right)$ of corning glass substrates were cleaned in acetone and isopropanol in an ultrasonic bath for $10 \mathrm{~min}$ each and then rinsed repeatedly with warm deionized water. A three-zone chemical vapor deposition (CVD) system with a horizontal ceramic tube (Zhengzhou Brother XD-1600MT Furnace Co., LTD, Zhengzhou, China; tube has $6 \mathrm{~cm}$ inner diameter and each zone is $20 \mathrm{~cm}$ in length [22]) was used to deposit the lead halides [20,21]. The outlet side of the ceramic tube is connected to a rotary vacuum pump, which achieves a base pressure of 0.05 mbar. An automated pressure regulator controls the deposition pressure. The inlet side of the ceramic tube is connected to a nitrogen gas $\left(\mathrm{N}_{2}\right)$ line, which passes through a mass flow controller (MFC) from the $\mathrm{N}_{2}$ cylinder. The schematic representation of the CVD furnace system is shown in Figure 1a, showing all the major components.

About 150 mg of lead (II) iodide (Cas No. 10101-63-0, yellow powder, purity, 99\%, Sigma-Aldrich Co., Saint Louis, MO, USA) or lead (II) chloride (Cas No. 7758-95-4, white powder, purity, 98\%, Sigma-Aldrich Co., Saint Louis, MO, USA) were used as vapor sources, separately. During deposition, the $\mathrm{PbI}_{2}$ or $\mathrm{PbCl}_{2}$ powder source was contained in ceramic boats and positioned at the center of the first zone, with substrates placed downstream of the tube onto flat silicon wafer supports. The respective positions of the sources and substrates are also illustrated in Figure 1a. 


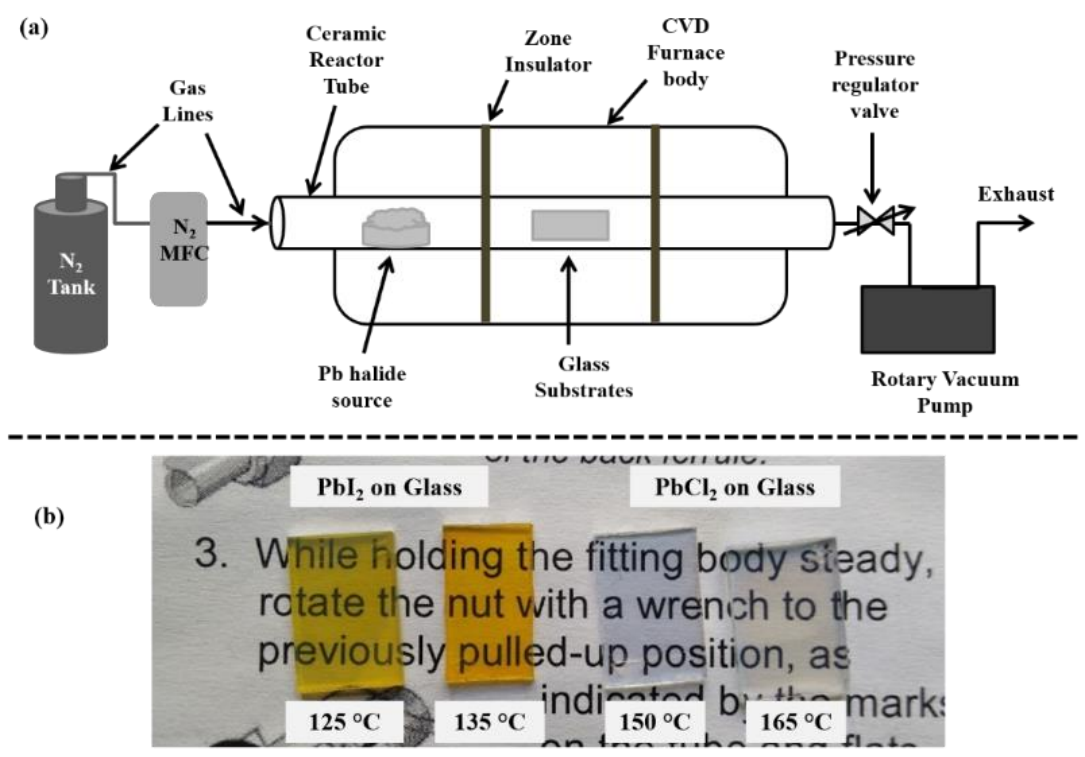

Figure 1. (a) Chemical vapor deposition (CVD) system schematic employed here showing all the important components; (b) Photographs of the as-deposited Pb halide films on glass at different deposition temperatures as shown $\left(\mathrm{PbI}_{2}\right.$ transparent yellow and $\mathrm{PbCl}_{2}$ transparent white).

For the $\mathrm{PbI}_{2}$ film deposition, the first zone with the $\mathrm{PbI}_{2}$ source was ramped up to a nominal temperature of $380^{\circ} \mathrm{C}$ for the source evaporation, with a ramping rate of $10^{\circ} \mathrm{C} / \mathrm{min}[20,21]$. Substrates were placed at optimized distances of 15 or $16 \mathrm{~cm}$ away from the source, downstream, in positions that reach nominal substrate temperatures of 135 or $125^{\circ} \mathrm{C}$, respectively, as measured using an external thermocouple prior to the deposition. Similar conditions for $\mathrm{PbCl}_{2}$ were followed except for the source sublimation temperature, which was $450^{\circ} \mathrm{C}$, and the substrates were placed at optimized distances of 16 or $17 \mathrm{~cm}$ away from the source with nominal substrate temperatures of 165 or $150^{\circ} \mathrm{C}$, respectively. These substrate temperatures were selected based on preliminary experiments during the deposition optimization of $\mathrm{Pb}$ halide film thickness. Only the first zone was heated during these depositions, and the different substrate temperatures were due to the temperature gradient from the heated first zone towards the tube outlet. The depositions were allowed to dwell for $40 \mathrm{~min}$ with pressure controlled and maintained at 300 mbar during this deposition under a continuous flow of $\mathrm{N}_{2}$ at 100 standard cubic centimeters per minute (sccm). Transparent yellowish $\mathrm{PbI}_{2}$ and whitish $\mathrm{PbCl}_{2}$ thin films were obtained, and no postdeposition treatments were performed on these thin films. Photographs of the films are shown in Figure $1 \mathrm{~b}$. The observed difference in color in the $\mathrm{PbI}_{2}$ and $\mathrm{PbCl}_{2}$ pairs is due to the thickness difference, where the thicker films are deposited at the higher temperatures.

\subsection{Characterization}

To study the phase composition and structure of these thin films, X-ray diffraction (XRD) was employed using a Panalytical Empyrean X-ray diffractometer (Malvern Panalytical Ltd. Malvern, Worcestershire, UK) with $\mathrm{Cu} \mathrm{K} \alpha 1$ radiation (1.5406 ̊), operated at an acceleration voltage of $45 \mathrm{kV}$ and $40 \mathrm{~mA}$ current. Samples were scanned over a $2 \theta$ range of $5^{\circ}-99^{\circ}$ with a scan step of $0.02626^{\circ}$. The morphology (surface and cross-sectional views) of the $\mathrm{Pb}$ halide layers was investigated using a field-emission gun scanning electron microscope (FEG-SEM, Zeiss Auriga, Jena, Germany) operated at acceleration voltages of $3-5 \mathrm{kV}$ and equipped with energy-dispersive $\mathrm{X}$-ray spectroscopy (EDS) facilities to probe the elemental composition. The samples were lightly coated with carbon to enhance image quality. The cross-sectional samples were prepared by breaking the glass substrate after making a deep scratch on the back side of the glass to break it easily. A Tecnai F20 FEG transmission electron microscopy (FEG-TEM, FEI, Hillsboro, OR, USA) operated at $200 \mathrm{kV}$ was used to examine the internal structure of the $\mathrm{PbI}_{2}$ platelets and allows for electron diffraction measurements. The samples for 
the TEM were obtained by scratching the surface of the film and dispersing the flakes in an ethanol solution by sonication, followed by dropping it onto a $\mathrm{Cu}$ grid that was dried under a lamp. For optical transmission measurements, an Ocean Optics UV-visible spectrophotometer (Ocean Insight, Orlando, FL, USA) was used with measurements taken from 250 to $1000 \mathrm{~nm}$ with a spectral resolution of $0.5 \mathrm{~nm}$. Thin film thicknesses were measured using a Veeco Dektak 6M Stylus thickness profiler (Veeco Instruments, Inc., Tucson, AZ, USA).

\section{Results and Discussion}

\subsection{Structural Properties of Lead Iodide Films}

The X-ray diffraction (XRD) patterns of the $\mathrm{PbI}_{2}$ thin films on glass substrates deposited at substrate temperatures of 125 and $135^{\circ} \mathrm{C}$ are shown in Figure 2a. The observed peaks $(2 \theta)$ at $12.7^{\circ}$, $25.6^{\circ}, 38.8^{\circ}$, and $52.5^{\circ}$ are assigned to the (001), (002), (003), and (004) diffraction planes, respectively, consistent with the results of previous reports $[7,8]$. These XRD patterns are indexed to the $2 \mathrm{H}$ hexagonal $(P 3 \bar{m} 1)$ structure $[7,8]$ of the crystalline $\mathrm{PbI}_{2}$ phase. For both samples, the $(001)$ peak is the most intense compared to other diffraction peaks, as shown in Figure 2a,b, indicating a preferential growth orientation along the (001) direction that is parallel to the $c$-axis of the hexagonal $\mathrm{PbI}_{2}$ unit cell $[7,8]$. This highly intense (001) peak demonstrates that these $\mathrm{PbI}_{2}$ films are highly textured as there appears to be no other family of planes in the XRD pattern such as the (110) [8]. The preferred growth orientation of $\mathrm{PbI}_{2}$ thin films is related to its growth mechanism, which follows a layer-by-layer growth through the van der Waals bonding along the $c$-axis $[1,7]$. Furthermore, the $\mathrm{PbI}_{2}$ thin film deposited at the higher substrate temperature of $135^{\circ} \mathrm{C}$ showed a slightly higher (001) peak intensity, as demonstrated in Figure $2 \mathrm{~b}$. This may be due to the improved crystallinity of the film due to higher deposition substrate temperature or a greater film thickness compared to its low-temperature counterpart. XRD patterns in Log intensity scale for the two $\mathrm{PbI}_{2}$ films are shown in Figure S1a on the Supplementary Materials.
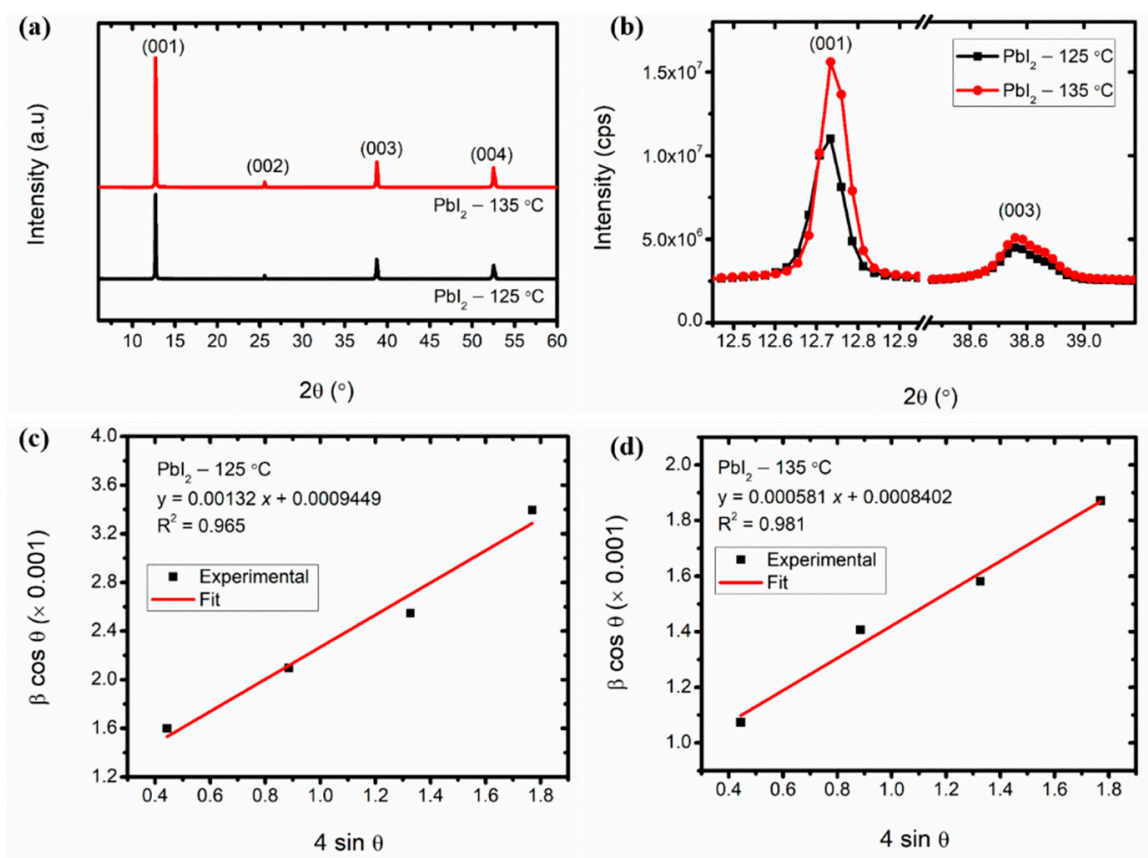

Figure 2. (a) Full $\mathrm{XRD}$ patterns of the $\mathrm{PbI}_{2}$ thin films on glass deposited at different substrate temperatures; (b) zoomed XRD patterns showing the two intense (001) and (003) peaks of the $\mathrm{PbI}_{2}$ films; (c,d) Williamson-Hall plots for crystallite size and strain estimation of the two $\mathrm{PbI}_{2}$ films. 
The XRD patterns were fitted to obtain peak information on the peak position and peak width (full width at half maximum). The peak position in degrees was used to estimate the planar d-spacing via Bragg's diffraction equation: $2 d_{h k l} \sin \theta=\lambda$, where $d_{h k l}$ is the planar spacing, $\theta$ is half the XRD peak position, and $\lambda$ is the $\mathrm{Cu} \mathrm{K \alpha 1}$ wavelength [23]. The planar d-spacing was in turn used to estimate the lattice constants of these films, summarized in Table 1. The lattice parameters are almost identical for the films, which is also indicated in Figure 2b, where there is no distinct shift in the XRD peak positions of the (001) and (003) planes. The sample grown at the higher substrate temperature of $135^{\circ} \mathrm{C}$ shows a slight lattice compression compared to the low substrate temperature sample $\left(125^{\circ} \mathrm{C}\right)$, which may be due to the compressive stress induced by the higher substrate temperature.

Table 1. Summary of X-ray diffraction information, including lattice parameters (constants), crystallite sizes, and strain of the two $\mathrm{PbI}_{2}$ films deposited at different substrate temperatures.

\begin{tabular}{ccccc}
\hline $\begin{array}{c}\text { Sample } \\
\text { Conditions }\end{array}$ & $\begin{array}{c}\text { Lattice } \\
\text { Parameter } \\
\text { ' } \boldsymbol{c} \text { ' }(\mathbf{n m})\end{array}$ & $\begin{array}{c}\text { Lattice } \\
\text { Parameter } \\
\mathbf{\prime} \boldsymbol{a} \boldsymbol{\prime}^{\prime}(\mathbf{n m})\end{array}$ & $\begin{array}{c}\text { Crystallite } \\
\text { Size } \\
\mathbf{( n m )}\end{array}$ & $\begin{array}{c}\text { Strain } \\
\left(\times \mathbf{1 0}^{-3}\right)\end{array}$ \\
\hline $125^{\circ} \mathrm{C}$ & 0.6959 & 0.4548 & 154.3 & 1.32 \\
$135^{\circ} \mathrm{C}$ & 0.6956 & 0.4547 & 172.4 & 0.581 \\
\hline
\end{tabular}

The vertical crystallite sizes of the films were also estimated using the Williamson-Hall (W-H) method, which takes into consideration the effect of strain. The $\mathrm{W}-\mathrm{H}$ equation relates the peak broadening to the crystallite size via the relation: $\beta_{d} \cos \theta=4 \varepsilon \sin \theta+(k \lambda / D)$, where $D$ is the crystallite size, $k$ is a constant (0.94), $\lambda$ is the $\mathrm{Cu} \mathrm{K} \alpha 1$ wavelength, $\beta_{d}$ is the full width at half maximum in radians (as discussed in [23]), $\theta$ is the peak position, and $\varepsilon$ is the strain parameter [23]. The $\mathrm{W}-\mathrm{H}$ equation is explained and derived in [23], and the crystallite size and strain are obtained through a linear plot of $\beta_{d} \cos \theta$ vs. $4 \sin \theta$, as shown in Figure 2 c,d. The crystallite sizes were calculated by equating the $y$-intercepts to $k \lambda / D$, and strain $(\varepsilon)$ is the slope of the linear fit. The fits for the two samples of $\mathrm{PbI}_{2}$ are shown in Figure 2c,d.

The estimated crystallite sizes of these samples are also included in Table 1 . The sample deposited at a $125{ }^{\circ} \mathrm{C}$ substrate temperature had a smaller crystallite size of about $154.3 \mathrm{~nm}$ compared to the sample deposited at the higher substrate temperature of $135^{\circ} \mathrm{C}$, which amounted to about $172.4 \mathrm{~nm}$. The increased crystallite size of the $135^{\circ} \mathrm{C}$ sample is evident in the higher XRD peak intensity (Figure 2b), indicating the superior crystallinity of this sample. The XRD data prove that the substrate temperature influences the crystallinity of the resulting $\mathrm{PbI}_{2}$ films and therefore reiterates the importance of investigating the crystal structure of films deposited at different substrate temperatures, which, in this case, is position-dependent and has an effect on the film thickness, as will be discussed in the next section.

\subsection{Morphology of Lead Iodide Films}

The scanning electron microscopy (SEM) micrographs of the as-deposited $\mathrm{PbI}_{2}$ films deposited at different substrate temperatures are provided in Figure $3 \mathrm{a}, \mathrm{b}$. The film morphology is similar for both deposition conditions and is characterized by flat and compact grains, as shown by the higher-magnification SEM micrographs in Figure $3 a, b$. These flat grains are formed from coalesced hexagonal platelet grains, and this is a common morphology of vapor-deposited $\mathrm{PbI}_{2}$ films $[1,7,8,11]$. Some of these hexagonal platelet grains grow at angles with respect to the film surface, with some lying perpendicular to the film surface, as shown by the selected area in Figure 3a,b. 

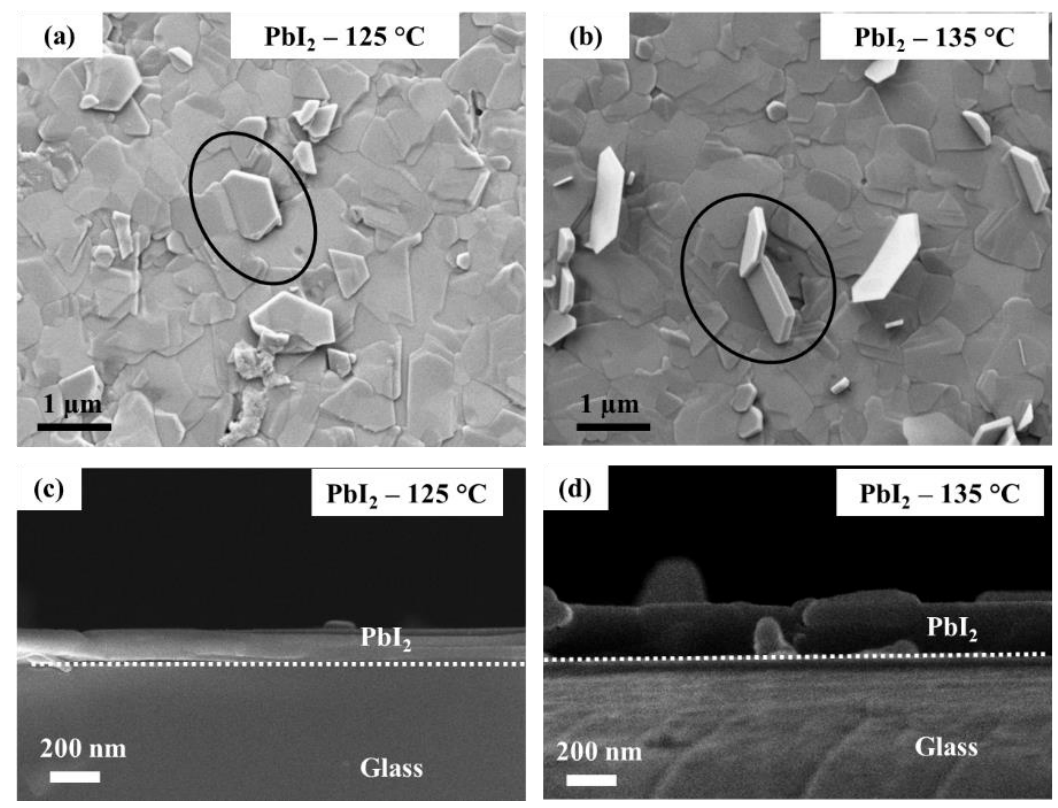

Figure 3. Planar $\mathrm{SEM}$ micrographs (high magnification) of $\mathrm{PbI}_{2}$ thin films deposited from different substrate temperatures: (a) $125^{\circ} \mathrm{C}$ and (b) $135^{\circ} \mathrm{C}$, as shown on the micrographs; (c,d) corresponding cross-sectional SEM of the $\mathrm{PbI}_{2}$ thin films on glass substrates.

The concentration of these surface platelets was higher for the sample grown at a higher substrate temperature, which is clearer in the lower-magnification micrograph in Figure S2b. These films are uniform over large areas, as evident from the lower-magnification SEM micrographs in Figure S2a,b. This is an indication of the suitability of the low-pressure CVD method for the deposition of $\mathrm{PbI}_{2}$ films with a tailored morphology at different substrate temperatures.

The compactness of the grains is also evidenced by the fact that there are no clear observable grain boundaries between the grains. The histograms showing the distribution of the measured lateral grain sizes are given in Figure $\mathrm{S} 2 \mathrm{c}, \mathrm{d}$. The $\mathrm{PbI}_{2}$ film deposited at 125 and $135^{\circ} \mathrm{C}$ has an average lateral grain size of $588.7 \pm 117.6 \mathrm{~nm}$ and $734.2 \pm 144.8 \mathrm{~nm}$, respectively. The lateral grain sizes are larger than the vertical crystallite sizes estimated from the XRD results. This implies that these grains are composed of smaller crystallites. The flatness of the $\mathrm{PbI}_{2}$ film morphology was also depicted in the cross-sectional SEM micrographs shown in Figure 3c,d.

These films show a homogeneous film thickness with minimal roughness, attributed to the surface platelets observed in the planar-view SEM micrographs in Figure 3a,b. The thickness of the $\mathrm{PbI}_{2}$ film deposited at $125^{\circ} \mathrm{C}$ was measured to be about $150 \mathrm{~nm}$ from the SEM micrograph (Figure 3c), which is thinner than the sample deposited at a substrate temperature of $135^{\circ} \mathrm{C}$ that has a thickness of about $290 \mathrm{~nm}$ (Figure 3d). These thickness values agree with those measured by profilometry. The thicker film produced at a higher substrate temperature is due to the faster deposition rate and the fact that the substrates were closer to the source than the lower temperature position. This observation confirms that the film thickness can be controlled by varying the substrate temperature and distance between source and substrate.

These films grow flat on the surface of the glass with no clear grain boundaries across the film thickness. This again agrees with the compact grain nature observed in the planar SEM micrographs. The film thickness is slightly less than the average grain size for both deposition conditions, suggesting a faster lateral grain growth than vertical growth, which is ascribed to the minimized surface energy of the crystalline facets [24]. This faster lateral grain growth is clearly shown in the longer lateral dimension of the surface platelets in Figure $3 a, b$, where a platelet grows longer than a micron $(1 \mu \mathrm{m})$ size compared to the film thickness. This is attributed to the growth mechanism of $\mathrm{PbI}_{2}$ platelet grains. The growth follows a layer-by-layer pattern of repeating $\mathrm{I}-\mathrm{Pb}-\mathrm{I}$ monolayers that are covalently bonded 
and separated by a weak van der Waals bonding $[20,21,24]$. During growth, these monolayers are stacked perpendicular to the $c$-axis and parallel to the surface leading to a flat film surface. This flatness of the $\mathrm{PbI}_{2}$ film was also realized due to the flat surface of the glass substrate as a rough surface may lead to tilted grains of $\mathrm{PbI}_{2}$ [24]. This implies that the choice of the substrate determines the resulting morphology of the $\mathrm{PbI}_{2}$ film.

Transmission electron microscopy (TEM) was used to probe the morphology and crystal structure of these platelet grains. The TEM samples were prepared by scraping off the surface of the films to increase the possibility of getting platelets. A low-resolution TEM micrograph of the platelets is shown in Figure $4 \mathrm{a}$, where a bundle of platelets is clearly visible. The high-resolution TEM micrograph in Figure $4 \mathrm{~b}$ shows that the platelets are highly crystalline, with the measured interplanar spacing of $0.339 \mathrm{~nm}$ averaged over six atomic planes (Figure $4 \mathrm{~b}$ ), belonging to the (101) family of the plane of the hexagonal $\mathrm{PbI}_{2}$ structure [14,25]. The selected area electron diffraction (SAED) pattern in Figure 4c further proves that these platelet grains are highly crystalline with diffraction spots that form hexagons, in which the spots forming the first hexagon are indexed to the (100) planes [14,25]. The diffraction spot patterns that lie on the second hexagon with respect to the center are indexed to the (110) planes. The hexagonal spot pattern of the SAED proves the crystalline nature of the $\mathrm{PbI}_{2}$ films, in agreement with the XRD data.

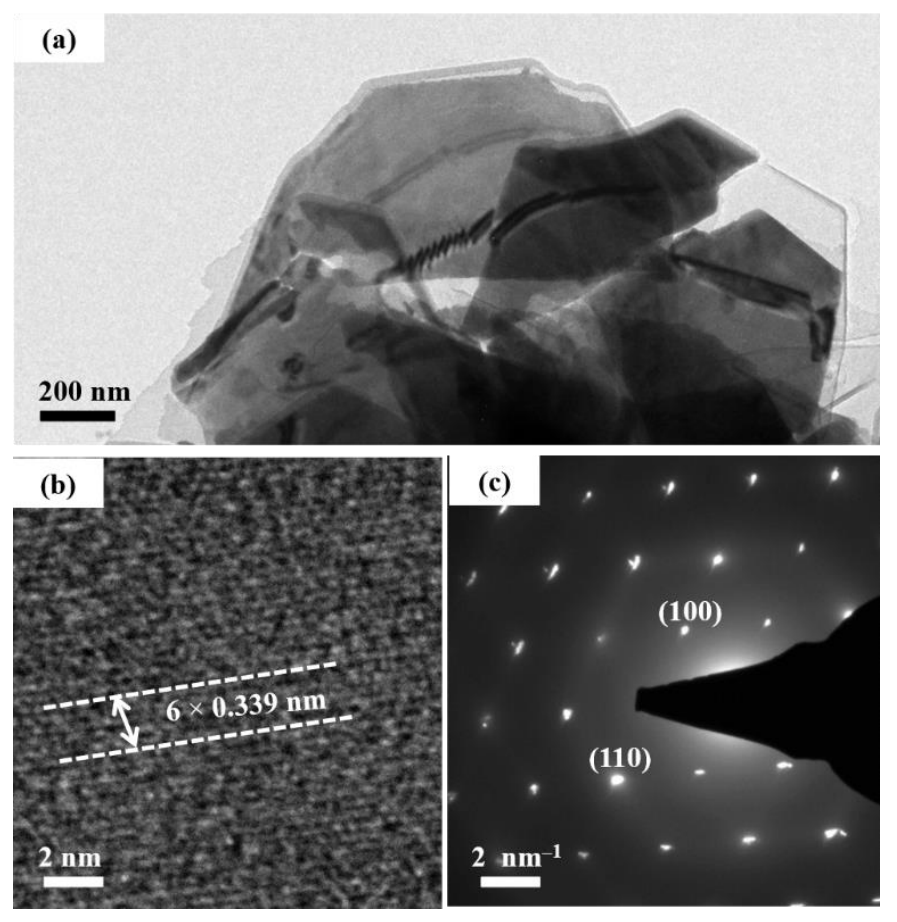

Figure 4. (a) Low-resolution TEM micrograph of $\mathrm{PbI}_{2}$ platelets; (b) high-resolution TEM micrograph of the platelet in (a) showing atomic planes of $\mathrm{PbI}_{2} ;$ (c) selected area electron diffraction pattern of the $\mathrm{PbI}_{2}$ platelet showing a single-crystalline nature.

Elemental composition was verified by energy-dispersive X-ray spectroscopy (EDS) taken at various positions of the two samples, with the spectra shown in Figure $\mathrm{S} 3 \mathrm{a}, \mathrm{b}$. The $\mathrm{Pb} / \mathrm{I}$ atomic concentration for the $125^{\circ} \mathrm{C}$ deposited sample was about 0.681 and for the $135^{\circ} \mathrm{C}$ sample was 0.651 , both higher than the stoichiometric $\mathrm{PbI}_{2}$, which has a $\mathrm{Pb} / \mathrm{I}$ value of 0.5 . These results show that there is an excess of lead in these films, which suggests the presence of metallic lead $\left(\mathrm{Pb}^{0}\right)$, i.e., unbonded lead atoms. These results demonstrate the successful deposition of high quality and compact $\mathrm{PbI}_{2}$ films with controllable morphology and thickness, which is beneficial for perovskite preparation, as the starting $\mathrm{Pb}$ halide layer determines the final properties of the resulting perovskite film during the two-step perovskite deposition process. 


\subsection{Structural Properties of Lead Chloride Films}

Two different substrate temperatures were also investigated for the deposition of lead chloride $\left(\mathrm{PbCl}_{2}\right)$ films and were 150 and $165{ }^{\circ} \mathrm{C}$. These substrate temperatures are higher than the $\mathrm{PbI}_{2}$ counterparts, mainly because the sublimation temperature of $\mathrm{PbCl}_{2}$ was higher $\left(450^{\circ} \mathrm{C}\right)$ compared to that of $\mathrm{PbI}_{2}\left(380^{\circ} \mathrm{C}\right)$. XRD patterns of the $\mathrm{PbCl}_{2}$ reveal crystalline films with intense peaks for both samples, as shown in Figure 5 a. The observed peaks at $22.25^{\circ}, 24.67^{\circ}, 25.21^{\circ}, 32.55^{\circ}, 40.05^{\circ}$, and $46.63^{\circ}$ $2 \theta$ angle are assigned to the (101), (020), (111), (121), (004) and (033) diffracting planes, respectively, based on the International Centre for Diffraction Data (ICDD), Data No. 00-001-0536 [26]. These patterns are indexed to the orthorhombic crystal system, space group Pnma of polycrystalline $\mathrm{PbCl}_{2}$ films $[27,28]$. XRD patterns in Log intensity scale for the two $\mathrm{PbCl}_{2}$ films are shown in Figure $\mathrm{S} 1 \mathrm{~b}$ on the Supplementary Materials.
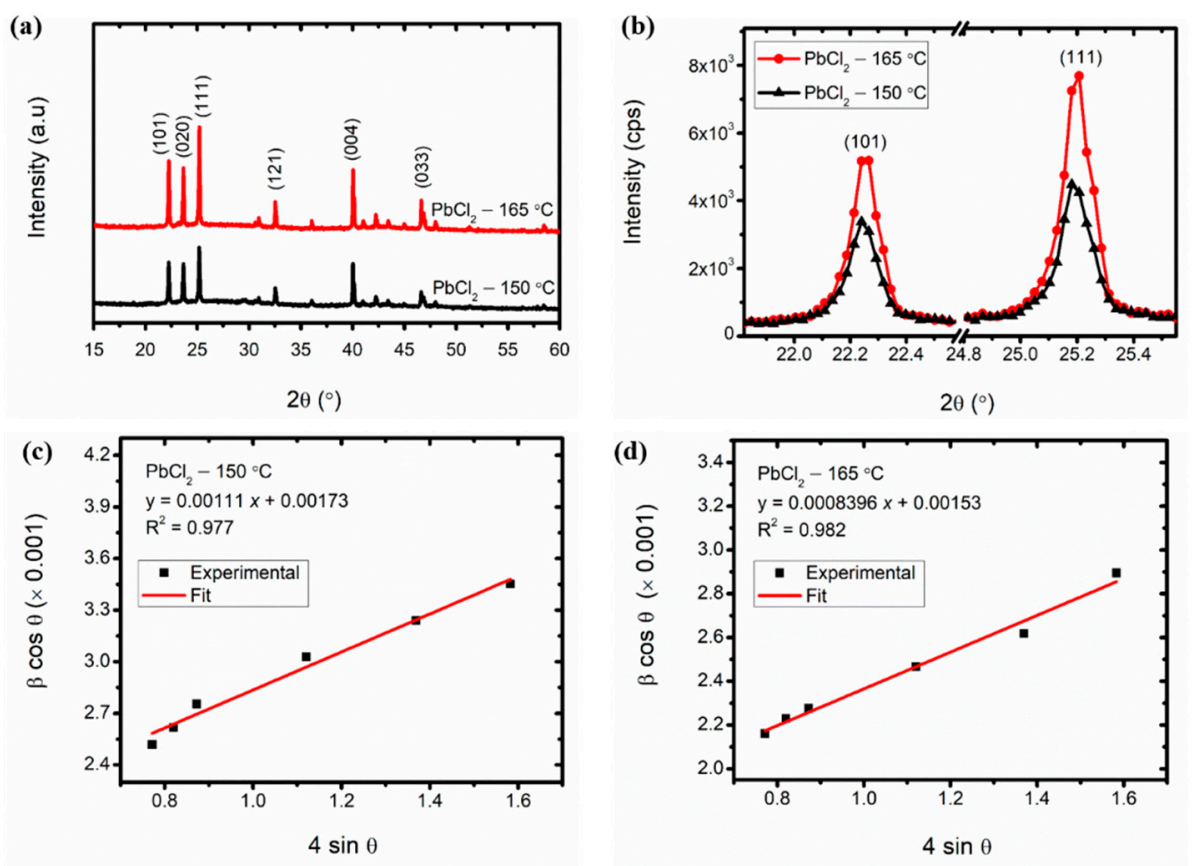

Figure 5. (a) Full $\mathrm{XRD}$ patterns of $\mathrm{PbCl}_{2}$ thin films on glass, deposited at different substrate temperatures; (b) zoomed XRD patterns showing the two intense (101) and (111) peaks of the $\mathrm{PbCl}_{2}$ films; (c,d) Williamson-Hall plots for crystallite size and strain estimation of the two $\mathrm{PbCl}_{2}$ films.

The (111) planes show high peak intensity for both samples (Figure 5a), but in general, these $\mathrm{PbCl}_{2}$ films show poor texture compared to the $\mathrm{PbI}_{2}$ films. Comparing the two $\mathrm{PbCl}_{2}$ deposition conditions in Figure $5 b$, the samples show no significant peak shift where the sample deposited at a higher substrate temperature of $165^{\circ} \mathrm{C}$ has a higher peak intensity that suggests superior crystallinity. The summary of the lattice parameters is given in Table 2, as calculated for the orthorhombic crystal phase. There is a slight lattice compression for the sample deposited at the higher substrate temperature $\left(165^{\circ} \mathrm{C}\right)$ compared to the sample deposited at $150{ }^{\circ} \mathrm{C}$.

Table 2. Summary of XRD data including lattice parameters $(a, b$, and $c)$, crystallite sizes, and strain of the two orthorhombic $\mathrm{PbCl}_{2}$ thin films deposited at different substrate temperatures.

\begin{tabular}{cccccc}
\hline $\begin{array}{c}\text { Sample } \\
\text { Conditions }\end{array}$ & $\boldsymbol{a}(\mathbf{n m})$ & $\boldsymbol{b}(\mathbf{n m})$ & $\boldsymbol{c}(\mathbf{n m})$ & $\begin{array}{c}\text { Crystallite } \\
\text { Size }(\mathbf{n m})\end{array}$ & $\begin{array}{c}\text { Strain } \\
\left(\times \mathbf{1 0}^{-3}\right)\end{array}$ \\
\hline $150^{\circ} \mathrm{C}$ & 0.4459 & 0.7575 & 0.9002 & 84.7 & 1.11 \\
$165^{\circ} \mathrm{C}$ & 0.4458 & 0.7575 & 0.9001 & 94.7 & 0.839 \\
\hline
\end{tabular}


The crystallite sizes of these films were also estimated via the $\mathrm{W}-\mathrm{H}$ method, as discussed for the $\mathrm{PbI}_{2}$ structure. The estimated crystallite sizes for the two samples are also provided in Table 2 and the plots are shown in Figure $5 \mathrm{c}, \mathrm{d}$. The $\mathrm{PbCl}_{2}$ film deposited at $150{ }^{\circ} \mathrm{C}$ showed smaller crystallites, with an average value of about $84.7 \mathrm{~nm}$ compared to the sample deposited at $165{ }^{\circ} \mathrm{C}$, with an average crystallite size of $94.7 \mathrm{~nm}$. The trend in these results is similar to those observed for $\mathrm{PbI}_{2}$ films with low substrate deposition, resulting in a smaller crystallite size. This is related to crystallite growth that is limited by the size of lateral grains and the film thickness, as is the case for $\mathrm{PbCl}_{2}$ films, where a higher substrate temperature deposition results in thicker films with larger lateral grains than low substrate temperature deposited films. The sample deposited at $165^{\circ} \mathrm{C}$ also shows a low strain from the W-H estimation. These XRD results confirm that highly crystalline $\mathrm{PbCl}_{2}$ thin films can be achieved by the low-pressure CVD method with control of crystallinity by tuning the substrate temperature. The success of depositing high-quality $\mathrm{PbCl}_{2}$ films provides options for the preparation of $\mathrm{Cl}$-doped hybrid perovskite films.

\subsection{Morphology of Lead Chloride Films}

High-magnification planar SEM micrographs of the $\mathrm{PbCl}_{2}$ thin films deposited at substrate temperatures of 150 and $165{ }^{\circ} \mathrm{C}$ are shown in Figure $6 \mathrm{a}, \mathrm{b}$, respectively. The morphology of these films is very distinct from that of the lead iodide films. These $\mathrm{PbCl}_{2}$ films have well defined semispherical grains forming a continuous compact film. Some of the grains grew into scattered nanowires (selected regions in Figure $6 a, b$ ), with the nanowire density dependent on the substrate temperature. The film morphology is uniform over large areas, as shown on the lower-magnification micrographs in Figure S4a,b. The lateral average grain size was estimated from the SEM micrographs, and the respective grain size distribution histograms are provided in Figure $\mathrm{S} 4 \mathrm{c}, \mathrm{d}$. The average grain size of the $\mathrm{PbCl}_{2}$ thin film deposited at a lower substrate temperature $\left(150{ }^{\circ} \mathrm{C}\right)$ is about $344.8 \pm 111.4 \mathrm{~nm}$ (Figure S4c), which is smaller than that of the $\mathrm{PbCl}_{2}$ film deposited at $165^{\circ} \mathrm{C}$ with an average grain size of $386.7 \pm 119.5 \mathrm{~nm}$ (Figure S4d). These results are similar to the trend observed for the $\mathrm{PbI}_{2}$ films.
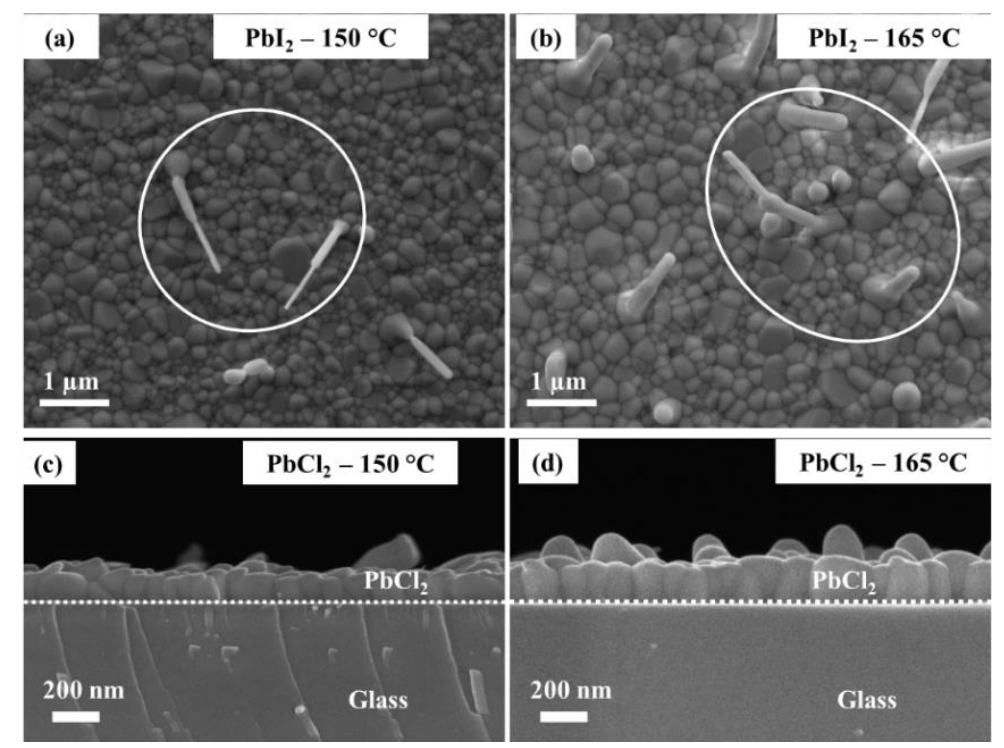

Figure 6. Planar SEM micrographs of the two $\mathrm{PbCl}_{2}$ thin films deposited at different substrate temperatures: (a) 150 and (b) $165{ }^{\circ} \mathrm{C}$, as shown on the micrographs; (c,d) cross-sectional SEM micrographs of the $\mathrm{PbCl}_{2}$ films deposited at different substrate temperatures as shown.

This enlarged average grain size at a higher substrate temperature is consistent with the increase in $\mathrm{PbCl}_{2}$ nanowire density, as shown in Figure $6 \mathrm{~b}$ and Figure S3b. The high substrate temperature could be providing sufficient energy to enlarge the grain sizes, which in turn results in the growth of 
nanowires on the surface of the film. The reliance of the nanowire growth on the substrate temperature has been reported before where catalysts were employed [29-31]. It is clearly visible in Figure $6 b$ that these nanowires nucleate from larger $\mathrm{PbCl}_{2}$ grains, hence their higher density for the sample with a larger average grain size. The formation mechanism of these nanowire growths is unclear, but it can be supposed that the $\mathrm{PbCl}_{2}$ grain growth has a saturation stage in the lateral direction. At this saturation stage, the $\mathrm{PbCl}_{2}$ protrude outwards where there may be free energy and hence form the nanowires [29-31]. These results confirm that with low-pressure CVD, different structures of lead halide can be formed by tuning the substrate temperature.

The cross-sectional SEM micrographs of the $\mathrm{PbCl}_{2}$ films are given in Figure $6 \mathrm{c}, \mathrm{d}$, where a homogeneous film thickness is observed for both samples. The $\mathrm{PbCl}_{2}$ grains are more columnar in shape, and there are grains protruding on the film surface, especially for the film deposited at $165{ }^{\circ} \mathrm{C}$ (Figure 6d). These protruding grains are an indication of the nanowire nucleation on the grains. The thickness of the $\mathrm{PbCl}_{2}$ film deposited at $150^{\circ} \mathrm{C}$ amounts to approximately $160 \mathrm{~nm}$ (Figure 6c) and that of the film deposited at $165{ }^{\circ} \mathrm{C}$ was measured to be about $210 \mathrm{~nm}$ (Figure $6 \mathrm{~d}$ ).

EDS measurements for chemical composition taken on these two $\mathrm{PbCl}_{2}$ samples confirmed the presence of lead and chlorine in the films (Figure S5a,b). The EDS spectra were acquired on large surface areas of the films for better statistics. The $\mathrm{Pb} / \mathrm{Cl}$ atomic concentration for the film deposited at a substrate temperature of $150{ }^{\circ} \mathrm{C}$ was found to be 0.579 , and for the film deposited at $165^{\circ} \mathrm{C}$ was found to be 0.519 . These values are closer to the stoichiometric value of 0.5 for $\mathrm{PbCl}_{2}$ compounds, which is better than that obtained for $\mathrm{PbI}_{2}$ films, suggesting less metallic lead in the $\mathrm{PbCl}_{2}$ films. The EDS results further confirm the successful deposition of high-quality lead chloride films by the low-pressure CVD method.

\subsection{Optical Properties of the Lead Halide Films}

The optical behavior of the $\mathrm{Pb}$ halide thin films was evaluated from UV-vis spectroscopy in the region $250-900 \mathrm{~nm}$. The transmittance spectra of the $\mathrm{PbI}_{2}$ and $\mathrm{PbCl}_{2}$ films are shown in Figure $7 \mathrm{a}, \mathrm{b}$, respectively. The $\mathrm{PbI}_{2}$ films have high light transmittance at wavelengths longer than $500 \mathrm{~nm}$, Figure $7 \mathrm{a}$, whereas the $\mathrm{PbCl}_{2}$ films transmit over the entire visible range, i.e., wavelengths longer than $350 \mathrm{~nm}$ as shown in Figure $7 \mathrm{~b}$. For both compounds, the expected increased transmittance for the thinner films is evident. Furthermore, the increased film thickness is also accompanied by the observed increase in the number of interference fringes for both compounds.

The optical band gap $\left(E_{\mathrm{g}}\right)$ of the $\mathrm{Pb}$-halide films was estimated from the Tauc relation: $(\alpha h v)^{2}=\mathrm{A}\left(h v-E_{\mathrm{g}}\right)$, assuming a direct band gap, where $\alpha$ is the absorption coefficient, $h v$ is the incident photon energy in $\mathrm{eV}$, and $\mathrm{A}$ is a constant [7]. The band gap is extracted from the linear part of the plot of $(\alpha h v)^{2}$ vs. $h v$, where it intercepts the $x$-axis $(h v)$, in which $(\alpha h v)^{2}=0$, as shown in Figure $7 \mathrm{c}, \mathrm{d}$. The extracted optical band gaps were found to be similar at 2.43 and $2.41 \mathrm{eV}$ for the $\mathrm{PbI}_{2}$ films deposited at 125 and $135{ }^{\circ} \mathrm{C}$ (Figure 7c), respectively, which is in the range of previously reported values for $\mathrm{PbI}_{2}$ thin films [1,7]. The $\mathrm{PbCl}_{2}$ films had a wide optical band gap with similar values of 4.26 and $4.25 \mathrm{eV}$ for films deposited at 150 and $165^{\circ} \mathrm{C}$ (Figure $7 \mathrm{~d}$ ), respectively. These results show that $\mathrm{PbI}_{2}$ films are wide band gap semiconductors and $\mathrm{PbCl}_{2}$ films are insulators. 
(1)
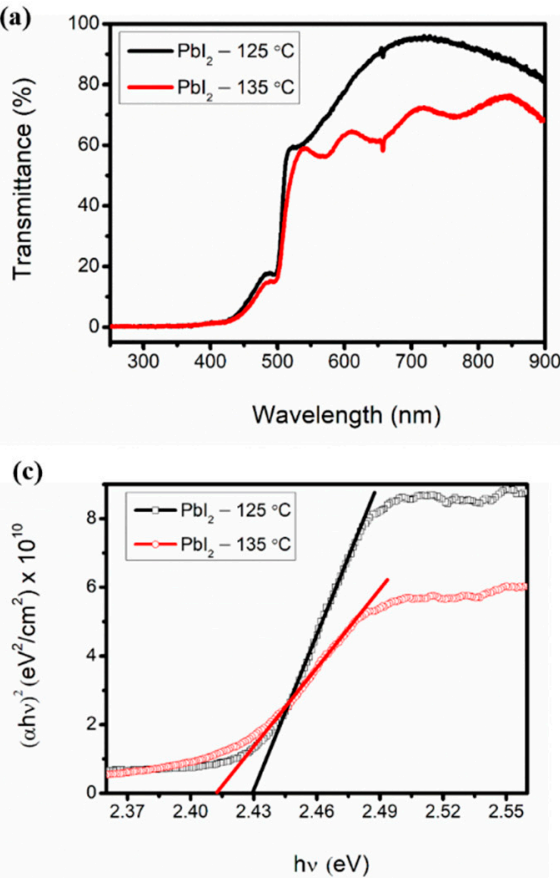

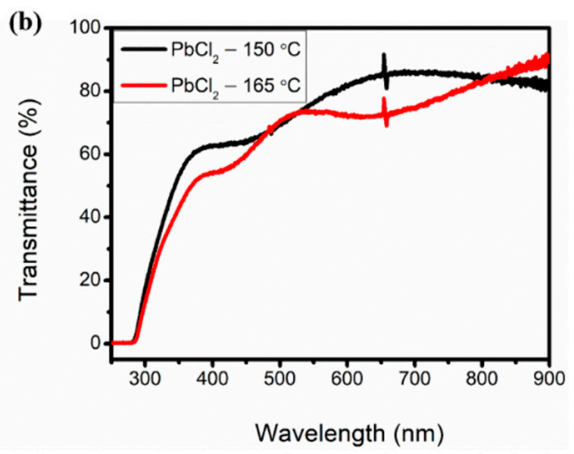

(d)

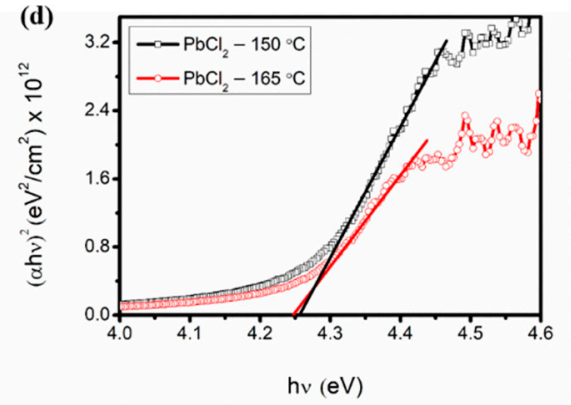

Figure 7. (a) UV-vis transmittance spectra of $\mathrm{PbI}_{2}$ thin films on glass; (b) UV-vis transmittance spectra of $\mathrm{PbCl}_{2}$ thin films on glass; (c) Tauc plots of $\mathrm{PbI}_{2}$ films; and (d) Tauc plots of $\mathrm{PbCl}_{2}$ films.

\section{Conclusions}

In conclusion, the successful deposition of high-quality crystalline films of lead iodide and lead chloride was realized through a low-pressure chemical vapor deposition method, offering a low-cost alternative for the preparation of precursor films for hybrid perovskite thin films. Highly textured $\mathrm{PbI}_{2}$ films with large crystallite sizes of 154.3 and $172.4 \mathrm{~nm}$ were achieved for films deposited at substrate temperatures of 125 and $135^{\circ} \mathrm{C}$, respectively. Large lateral grain sizes were also observed for these $\mathrm{PbI}_{2}$ films, as measured from the SEM micrographs, with an average grain size of $588.7 \pm 117.6 \mathrm{~nm}$ for the film deposited at $125^{\circ} \mathrm{C}$ and $734.2 \pm 144.8 \mathrm{~nm}$ for a sample deposited at $125^{\circ} \mathrm{C} . \mathrm{PbCl}_{2}$ showed a reduced texture in the XRD patterns with smaller crystallite sizes than that of the $\mathrm{PbI}_{2}$ films, with values of 84.7 and $94.7 \mathrm{~nm}$ for the films deposited at 150 and $165{ }^{\circ} \mathrm{C}$, respectively. The $\mathrm{PbCl}_{2}$ films have a columnar grain shape compared to the flat platelet grains of the $\mathrm{PbI}_{2}$ films, with an average grain size of $344.8 \pm 111.4 \mathrm{~nm}$ and $386.7 \pm 119.5 \mathrm{~nm}$ for the films deposited at 150 and $165^{\circ} \mathrm{C}$, respectively. These large grain sizes for these lead halides films are beneficial for the conversion to large-grain perovskite films, which will be beneficial for the performance and stability of perovskite solar cells. Optically, the $\mathrm{PbI}_{2}$ films showed a band gap of about $2.4 \mathrm{eV}$, confirming its semiconducting nature. The $\mathrm{PbCl}_{2}$ has a wide band gap of $4.3 \mathrm{eV}$, which shows the insulating properties of this material.

Supplementary Materials: The following are available online at http://www.mdpi.com/2079-6412/10/12/1208/s1, Figure S1: XRD patterns in Log intensity scale for the lead halides thin films deposited at different temperatures: (a) $\mathrm{PbI}_{2}$ thin films and (b) $\mathrm{PbCl}_{2}$ thin films, Figure S2: Low-magnification planar SEM micrographs of $\mathrm{PbI}_{2}$ thin films deposited from different substrate temperatures: (a) 125 and (b) $135^{\circ} \mathrm{C}$; Histograms showing the measured lateral grain size distribution of the two $\mathrm{PbI}_{2}$ thin films: (c) 125 and (d) $135^{\circ} \mathrm{C}$, Figure S3: EDS spectra of the $\mathrm{PbI}_{2}$ film on glass substrates deposited at different substrate temperatures: (a) 125 and (b) $135^{\circ} \mathrm{C}$, Figure S4: Low-magnification planar SEM micrographs of $\mathrm{PbCl}_{2}$ thin films deposited from different substrate temperatures: (a) 150 and (b) $165^{\circ} \mathrm{C}$; Histograms showing the measured lateral grain size distribution of the two $\mathrm{PbI}_{2}$ thin films: (c) 150 and (d) $165^{\circ} \mathrm{C}$, Figure S5: EDS spectra of the $\mathrm{PbCl}_{2}$ film on glass substrates deposited at different substrate temperatures: (a) 150 and (b) $165^{\circ} \mathrm{C}$.

Author Contributions: Conceptualization, methodology, investigation, formal analysis, writing-original draft preparation, S.N.; conceptualization, methodology, writing-review and editing, supervision, project administration, C.J.A.; data curation, validation, formal analysis, T.F.M.; methodology, formal analysis, S.S.M. and C.J.O. All authors have read and agreed to the published version of the manuscript. 
Funding: This research was funded by the National Research Foundation of South Africa, Grant Nos. 93212, 92520, 103621.

Acknowledgments: The authors acknowledge the financial support of the University of the Western Cape (UWC) and the ARMSCOR DESUP project. The authors also thank the National Metrology Institute of South Africa and the Electron Microscopy Unit of UWC for the microscopy measurements.

Conflicts of Interest: The authors declare no conflict of interest.

\section{References}

1. Ha, S.T.; Liu, X.; Zhang, Q.; Giovanni, D.; Sum, T.C.; Xiong, Q. Synthesis of organic-inorganic lead halide perovskite nanoplatelets: Towards high-performance perovskite solar cells and optoelectronic devices. Adv. Opt. Mater. 2014, 2, 838-844. [CrossRef]

2. Kojima, A.; Teshima, K.; Shirai, Y.; Miyasaka, T. Organometal halide perovskites as visible-light sensitizers for photovoltaic cells. J. Am. Chem. Soc. 2009, 131, 6050-6051. [CrossRef]

3. Tang, Z.; Tanaka, S.; Ito, S.; Ikeda, S.; Taguchi, K.; Minemoto, T. Investigating relation of photovoltaic factors with properties of perovskite films based on various solvents. Nano Energy 2016, 21, 51-61. [CrossRef]

4. Chen, Q.; Zhou, H.; Hong, Z.; Luo, S.; Duan, H.-S.; Wang, H.-H.; Liu, Y.; Li, G.; Yang, Y. Planar heterojunction perovskite solar cells via vapor-assisted solution process. J. Am. Chem. Soc. 2014, 136, 622-625. [CrossRef] [PubMed]

5. Luo, P.; Liu, Z.; Xia, W.; Yuan, C.; Cheng, J.; Lu, Y. Uniform, stable, and efficient planar-heterojunction perovskite solar cells by facile low-pressure chemical vapor deposition under fully open-air conditions. ACS Appl. Mater. Interfaces 2015, 7, 2708-2714. [CrossRef]

6. Leyden, M.R.; Ono, L.K.; Raga, S.R.; Kato, Y.; Wang, S.; Qi, Y. High performance perovskite solar cells by hybrid chemical vapor deposition. J. Mater. Chem. A 2014, 2, 18742-18745. [CrossRef]

7. Sun, H.; Zhu, X.; Yang, D.; Yang, J.; Gao, X.; Li, X. Morphological and structural evolution during thermally physical vapor phase growth of $\mathrm{PbI}_{2}$ polycrystalline thin films. J. Cryst. Growth 2014, 405, 29-34. [CrossRef]

8. Schieber, M.; Zamoshchik, N.; Khakhan, O.; Zuck, A. Structural changes during vapor-phase deposition of polycrystalline-PbI ${ }_{2}$ films. J. Cryst. Growth 2008, 310, 3168-3173. [CrossRef]

9. Wei, Q.; Shen, B.; Chen, Y.; Xu, B.; Xia, Y.; Yin, J.; Liu, Z. Large-sized $\mathrm{PbI}_{2}$ single crystal grown by co-solvent method for visible-light photo-detector application. Mater. Lett. 2017, 193, 101-104. [CrossRef]

10. Xing, J.; Liu, X.F.; Zhang, Q.; Ha, S.T.; Yuan, Y.W.; Shen, C.; Sum, T.C.; Xiong, Q. Vapor phase synthesis of organometal halide perovskite nanowires for tunable room-temperature nanolasers. Nano Lett. 2015, 15, 4571-4577. [CrossRef]

11. Costa, J.C.S.; Azevedo, J.; Santos, L.M.N.B.F.; Mendes, A. On the deposition of lead halide perovskite precursors by physical vapor method. J. Phys. Chem. C 2017, 121, 2080-2087. [CrossRef]

12. Condeles, J.F.; Martins, T.M.; Dos Santos, T.C.; Brunello, C.A.; Mulato, M.; Rosolen, J.M. Fabrication and characterization of thin films of $\mathrm{PbI}_{2}$ for medical imaging. J. Non. Cryst. Solids 2004, 338-340, 81-85. [CrossRef]

13. Kong, W.; Li, G.; Liang, Q.; Ji, X.; Li, G.; Ji, T.; Che, T.; Hao, Y.; Cui, Y. Controllable deposition of regular lead iodide nanoplatelets and their photoluminescence at room temperature. Phys. E Low-Dimens. Syst. Nanostruct. 2018, 97, 130-135. [CrossRef]

14. Wang, Y.; Gan, L.; Chen, J.; Yang, R.; Zhai, T. Achieving highly uniform two-dimensional PbI $\mathrm{P}_{2}$ flakes for photodetectors via space confined physical vapor deposition. Sci. Bull. 2017, 62, 1654-1662. [CrossRef]

15. Zhang, Q.; Ha, S.T.; Liu, X.; Sum, T.C.; Xiong, Q. Room-temperature near-infrared high-Q perovskite whispering-gallery planar nanolasers. Nano Lett. 2014, 14, 5995-6001. [CrossRef]

16. Li, J.; Wang, H.; Chin, X.Y.; Dewi, H.A.; Vergeer, K.; Goh, T.W.; Lim, J.W.M.; Lew, J.H.; Loh, K.P.; Soci, C.; et al. Highly efficient thermally co-evaporated perovskite solar cells and mini-modules. Joule 2020, 4, 1035-1053. [CrossRef]

17. Lohmann, K.B.; Patel, J.B.; Rothmann, M.U.; Xia, C.Q.; Oliver, R.D.J.; Herz, L.M.; Snaith, H.J.; Johnston, M.B. Control over crystal size in vapor deposited metal-halide perovskite films. ACS Energy Lett. 2020, 5, 710-717. [CrossRef]

18. Liu, M.; Johnston, M.B.; Snaith, H.J. Efficient planar heterojunction perovskite solar cells by vapour deposition. Nature 2013, 501, 395-398. [CrossRef] 
19. Malinkiewicz, O.; Yella, A.; Lee, Y.H.; Espallargas, G.M.; Graetzel, M.; Nazeeruddin, M.K.; Bolink, H.J. Perovskite solar cells employing organic charge-transport layers. Nat. Photonics 2014, 8, 128-132. [CrossRef]

20. Ngqoloda, S.; Arendse, C.J.; Muller, T.F.; Miceli, P.F.; Guha, S.; Mostert, L.; Oliphant, C.J. Air-stable hybrid perovskite solar cell by sequential vapor deposition in a single reactor. ACS Appl. Energy Mater. 2020, 3, 2350-2359. [CrossRef]

21. Ngqoloda, S.; Arendse, C.J.; Muller, T.F.; Cummings, F.R.; Oliphant, C. Effect of HTL thickness on air processed CVD perovskite solar cells. Mater. Today Proc. 2020. [CrossRef]

22. Mouele, E.S.M.; Ngqoloda, S.; Pescetelli, S.; Di Carlo, A.; Dinu, M.; Vladescu, A.; Parau, A.C.; Agresti, A.; Braic, M.; Arendse, C.J.; et al. Spin coating immobilisation of C-N-TiO 2 Co-doped nano catalyst on glass and application for photocatalysis or as electron transporting layer for perovskite solar cells. Coatings 2020, 10, 29. [CrossRef]

23. Khorsand Zak, A.; Abd Majid, W.H.; Abrishami, M.E.; Yousefi, R. X-ray analysis of ZnO nanoparticles by Williamson-Hall and size-strain plot methods. Solid State Sci. 2011, 13, 251-256. [CrossRef]

24. Fu, F.; Kranz, L.; Yoon, S.; Löckinger, J.; Jäger, T.; Perrenoud, J.; Feurer, T.; Gretener, C.; Buecheler, S.; Tiwari, A.N. Controlled growth of $\mathrm{PbI}_{2}$ nanoplates for rapid preparation of $\mathrm{CH}_{3} \mathrm{NH}_{3} \mathrm{PbI}_{3}$ in planar perovskite solar cells. Phys. Status Solidi Appl. Mater. Sci. 2015, 212, 2708-2717. [CrossRef]

25. Klein, E.; Lesyuk, R.; Klinke, C. Insights into the formation mechanism of two-dimensional lead halide nanostructures. Nanoscale 2018, 10, 4442-4451. [CrossRef] [PubMed]

26. Hanawalt, J.D.; Rinn, H.W.; Frevel, L.K. Chemical analysis by X-ray diffraction. Ind. Eng. Chem. Anal. Ed. 1938, 10, 457-512. [CrossRef]

27. Sass, R.L.; Brackett, E.B.; Brackett, T.E. The crystal structure of lead chloride. J. Phys. Chem. 1963, 67, 2863-2864. [CrossRef]

28. Fan, L.; Ding, Y.; Luo, J.; Shi, B.; Yao, X.; Wei, C.; Zhang, D.; Wang, G.; Sheng, Y.; Chen, Y.; et al. Elucidating the role of chlorine in perovskite solar cells. J. Mater. Chem. A 2017, 5, 7423-7432. [CrossRef]

29. Schmidt, V.; Wittemann, J.V.; Gösele, U. Growth, thermodynamics, and electrical properties of silicon nanowires. Chem. Rev. 2010, 110, 361-388. [CrossRef]

30. Li, X.; Ni, J.; Zhang, R. A thermodynamic model of diameter- and temperature-dependent semiconductor nanowire growth. Sci. Rep. 2017, 7, 1-8. [CrossRef]

31. Ogino, T.; Yamauchi, M.; Yamamoto, Y.; Shimomura, K.; Waho, T. Preheating temperature and growth temperature dependence of InP nanowires grown by self-catalytic VLS mode on InP substrate. J. Cryst. Growth 2015, 414, 161-166. [CrossRef]

Publisher's Note: MDPI stays neutral with regard to jurisdictional claims in published maps and institutional affiliations.

(C) 2020 by the authors. Licensee MDPI, Basel, Switzerland. This article is an open access article distributed under the terms and conditions of the Creative Commons Attribution (CC BY) license (http://creativecommons.org/licenses/by/4.0/). 